\title{
Observation of mesospheric gravity waves at Comandante Ferraz Antarctica Station $\left(62^{\circ} \mathrm{S}\right)$
}

\author{
J. V. Bageston ${ }^{1}$, C. M. Wrasse ${ }^{2}$, D. Gobbi ${ }^{1}$, H. Takahashi ${ }^{1}$, and P. B. Souza ${ }^{1}$ \\ ${ }^{1}$ Instituto Nacional de Pesquisas Espaciais - INPE, São José dos Campos, Brazil \\ ${ }^{2}$ Universidade do Vale do Paraíba - UNIVAP - IP\&D, São José dos Campos, Brazil
}

Received: 27 February 2009 - Revised: 28 April 2009 - Accepted: 23 June 2009 - Published: 26 June 2009

\begin{abstract}
An airglow all-sky imager was operated at Comandante Ferraz Antarctica Station $\left(62.1^{\circ} \mathrm{S}, 58.4^{\circ} \mathrm{W}\right)$, between April and October of 2007. Mesospheric gravity waves were observed using the $\mathrm{OH}$ airglow layer during 43 nights with good weather conditions. The waves presented horizontal wavelengths between 10 and $60 \mathrm{~km}$ and observed periods mainly distributed between 5 and $20 \mathrm{~min}$. The observed phase speeds range between $5 \mathrm{~m} / \mathrm{s}$ and $115 \mathrm{~m} / \mathrm{s}$; the majority of the wave velocities were between 10 and $60 \mathrm{~m} / \mathrm{s}$. The waves showed a preferential propagation direction towards the southwest in winter (May to July), while during spring (August to October) there was an anisotropy with a preferential propagation direction towards the northwest. Unusual mesospheric fronts were also observed. The most probable wave source could be associated to orographic forcing, cold fronts or strong cyclonic activity in the Antarctica Peninsula.
\end{abstract}

Keywords. Atmospheric composition and structure (Airglow and aurora; Middle atmosphere - composition and chemistry) - Meteorology and atmospheric dynamics (Waves and tides)

\section{Introduction}

Gravity waves are now recognized to play an important role in the general circulation of the middle atmosphere. The dynamics of the polar mesosphere and lower thermosphere (MLT) are dominated by waves with periods ranging from a few minutes to months (Hibbins et al., 2007). Forcing by gravity waves cause reversals of the zonal mean jets and drive a mean meridional transport circulation that leads to a latitudinal temperature gradient opposite to that would be ex-

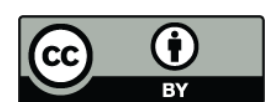

Correspondence to: J. V. Bageston (jvb@laser.inpe.br) pected in the absence of wave forcing (Fritts and Alexander, 2003).

Espy et al. (2004) reported seasonal variations in the gravity wave momentum flux over Halley Station, Antarctica $\left(75.6^{\circ} \mathrm{S}, 26.6^{\circ} \mathrm{W}\right)$. They used data from a sodium airglow imager and an Imaging Doppler Interferometer (IDI) radar for wind measurements. The authors showed a significant day-to-day variability in the momentum flux, with a strong westward momentum flux that turned eastward around the equinox. However, the authors did not discussed the characteristics of the observed gravity waves.

Most recently, Nielsen et al. (2006) used an all-sky imager at Halley Station, Antarctica $\left(75.5^{\circ} \mathrm{S}, 26.7^{\circ} \mathrm{W}\right)$ to show the first bore event observed at high latitudes. The characteristics of the bore in the $\mathrm{OH}$ layer were determined by applying a one-dimensional spatial S-transform analysis (Stockwell et al., 2006). Until now, no extensive analysis of gravity wave characteristics have been published based on airglow data collected in Antarctica.

This study presents and discusses the main characteristics of gravity waves observed at $62^{\circ} \mathrm{S}$ Antarctica, including wave morphology, horizontal wavelength, propagation direction, observed period and phase speed.

\section{Observations and methodology}

A six-month campaign focused on observations of gravity waves was conducted between 24 April and 24 October 2007 at Comandante Ferraz Antarctica Station $\left(62.1^{\circ} \mathrm{S}, 58.4^{\circ} \mathrm{W}\right)$ (hereafter CF), King George Island, Antarctica Peninsula.

The instrument used for the observations was an all-sky imaging system, that consists of a low cost CCD detector (SBIG, STL-1001E model) with high resolution, $1024 \times 1024$ pixels, $24.6 \times 24.6 \mathrm{~mm}$ and $\sim 50 \%$ of quantum efficiency in the near infrared (NIR). The CCD camera was coupled to a telecentric lens system, a fish eye lens and a 2 inch wide

Published by Copernicus Publications on behalf of the European Geosciences Union. 


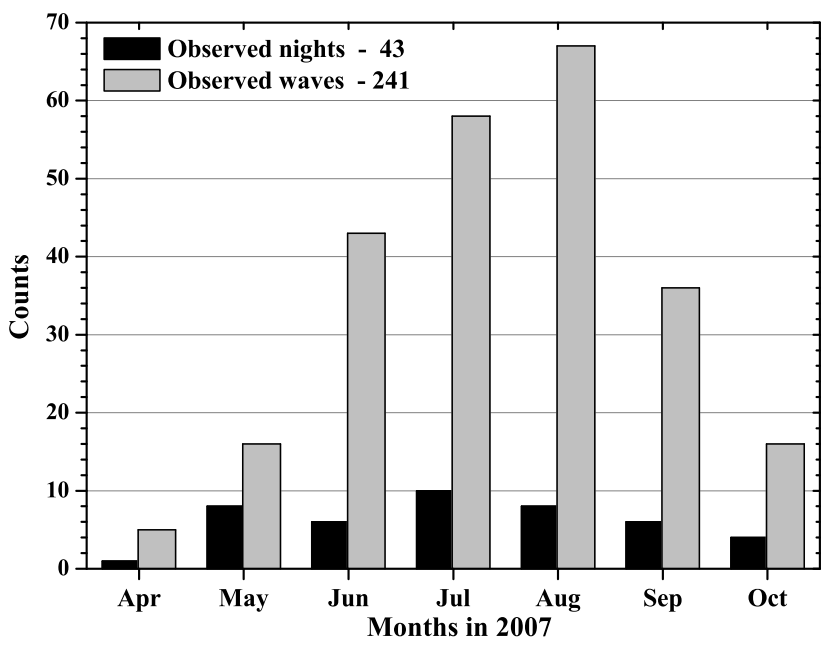

Fig. 1. Overview of the gravity wave campaign at CF showing the number of nights with observed waves (black) and also the total amount of waves in each month (gray).

band NIR optical filter $(715-930 \mathrm{~nm}$ with notch at $865.5 \mathrm{~nm}$ to suppress the $\mathrm{O}_{2}(0-1)$ emission).

The image was not binned, but cropped to $512 \times 512$ pixels due to the optical system limitations, producing an image size of $8 \times 8 \mathrm{~mm}$ on the CCD. Given this constraint, it was possible to obtain a covered area of $465 \times 465 \mathrm{~km}$ at the altitude of the $\mathrm{OH}$ emission layer $(87 \mathrm{~km})$, with a resolution of $1.5 \mathrm{~km} /$ pixel. The $\mathrm{OH}$ airglow images were then obtained with a time integration of $20 \mathrm{~s}$, allowing the system to obtain images with a high sampling rate $(\sim 38 \mathrm{~s})$.

During the campaign the weather was frequently cloudy and observations were made around the new moon periods totaling 87 nights overall. Gravity waves were identified on 43 nights, showing similar results to those presented by Espy et al. (2004) at Halley Station $\left(75.6^{\circ} \mathrm{S}, 26.6^{\circ} \mathrm{W}\right)$.

Figure 1 shows the distribution of the observed gravity waves and the number of nights with wave activity in each month. It is clearly seen in Fig. 1 that the majority of waves ( $\sim 85 \%)$ were observed between June and September. The maximum number of waves was observed in August, however July presented the major number of observed nights. The most significant characteristic was the large number of observed gravity waves (241) at CF, which is in agreement with the gravity wave events $(>400)$ mentioned by Nielsen et al. (2006) at southern polar latitudes.

Prior to data analysis the all-sky calibration was performed in order to obtain the lens function, which follows the method described by Garcia et al. (1997). The images were corrected for the warped field of view and a second order high-pass Butterworth filter was applied. The gravity wave parameters were obtained by using the standard 2-D FFT analysis (Garcia et al., 1997; Medeiros et al., 2003; Wrasse et al., 2007). The amplitude and phase of the cross spectrum was obtained

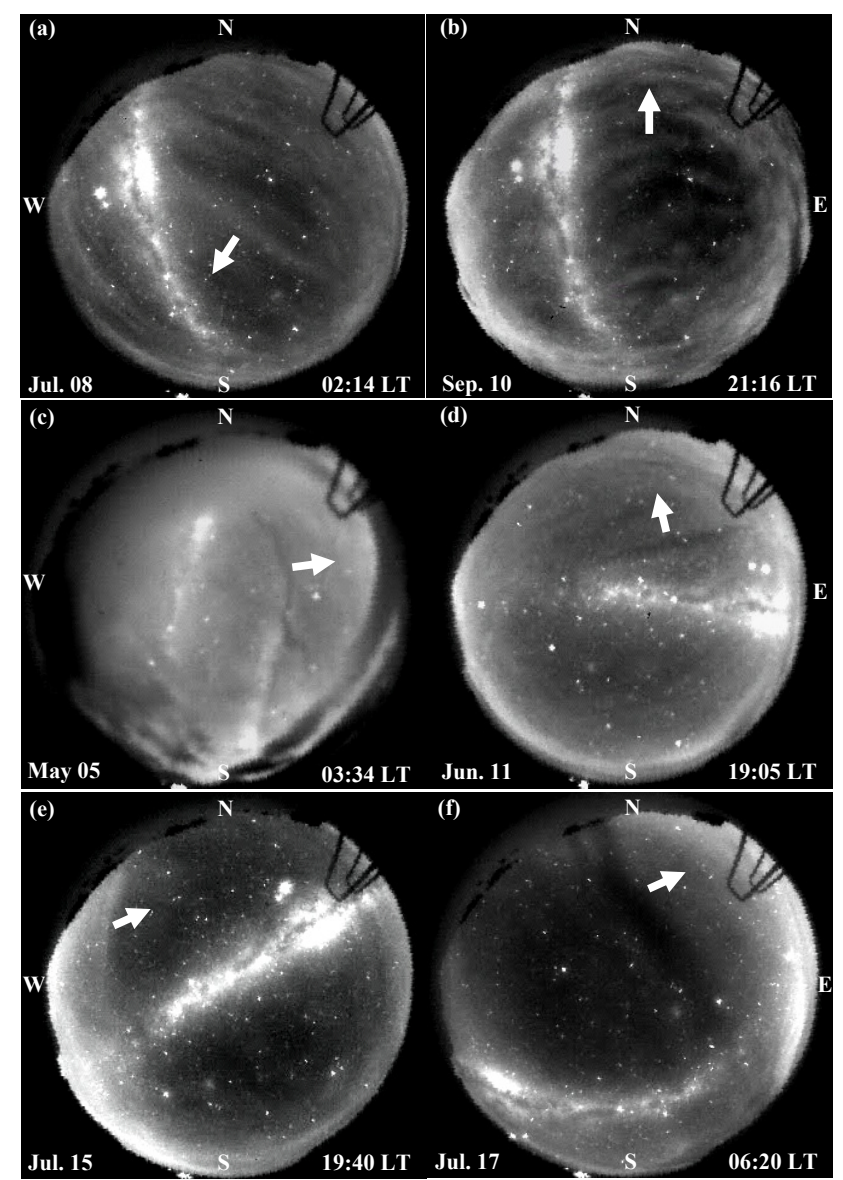

Fig. 2. Examples of atmospheric gravity waves observed at CF. Band type waves are presented in (a) and (b); solitary pulses in (c) and (d); mesospheric fronts in (e) and (f). The white arrows in the images indicate the wave propagation direction.

by a sequence of at least 4 images, which allows us to calculate the gravity wave horizontal wavelength $\left(\lambda_{h}\right)$, propagation direction $(\phi)$, observed phase speed $\left(c_{\text {obs }}\right)$ and period $\left(\tau_{\text {obs }}\right)$. In order to obtain the intrinsic wave parameters $\left(c_{\text {int }}\right.$ and $\left.\tau_{\text {int }}\right)$ we also would need the information of the background wind in the mesosphere region. Besides the gravity wave horizontal wavelength and propagation direction, the results presented in this work are only related to the observed phase speed $\left(c_{\mathrm{obs}}\right)$ and period $\left(\tau_{\mathrm{obs}}\right)$.

\section{Results and discussion}

In this section we present the results of the gravity wave morphology, horizontal wavelength, propagation direction, observed phase speed and period. Well-defined wave patterns were observed and the most common wave structures consisted of extensive large-scale waves known as bands. Section 3.1 shows some examples of gravity waves observed at 
CF, illustrating the diversity of wave morphology and dynamics. In Sect. 3.2 we discuss the distributions of the gravity waves parameters, while Sect. 3.3 shows the results of the wave propagation direction and observed phase speed.

\subsection{Morphology and dynamics}

The wave structures observed at CF consisted of bands (most of them), ripples, mesospheric fronts, and solitary pulses (both dark and white). Figure 2 shows some examples of the gravity waves observed at $\mathrm{CF}$ (north at the top of the image and east at the right). Three classes of waves are identifiable in the figure: bands (top panel), solitary pulses (middle panel) and mesospheric fronts (bottom panel). The corresponding date and local time (UT $-3 \mathrm{~h}$ ) are presented in each figure.

Figure 2a shows a band-type wave propagating toward the southwest with phase speed around $11 \mathrm{~m} / \mathrm{s}$ and horizontal wavelength of $23 \mathrm{~km}$. The wave in Fig. $2 \mathrm{~b}$ appears on the field of view around 20:50 LT (at the bottom of the image) with a semicircular shape and northward propagation direction, with a horizontal wavelength of $31 \mathrm{~km}$, observed phase speed and period of $63 \mathrm{~m} / \mathrm{s}$ and $8 \mathrm{~min}$, respectively.

Solitary pulses were an uncommon kind of waves and only 7 of them were detected during the campaign (including dark and white). Figure $2 \mathrm{c}$ and $\mathrm{d}$ shows two examples of dark fronts. Spectral analysis applied in a set of 6 images obtained during 6 min, including the image shown in Fig. 2c, resulted in an observed phase speed of $11 \mathrm{~m} / \mathrm{s}$. Figure $2 \mathrm{~d}$ presents an early stage of gravity wave seeding in the mesosphere, propagating northward with an observed phase speed of $26 \mathrm{~m} / \mathrm{s}$. The pulse was seen only during $14 \mathrm{~min}$ and travelled a distance of $\sim 22 \mathrm{~km}$ before disappearing.

Another type of observed wave was the so-called mesospheric front. Figure $2 \mathrm{e}$ shows a continuous bright front, propagating northeastward with an observed phase speed around $92 \mathrm{~m} / \mathrm{s}$, while Fig. 2f presents a wide dark front with a morphology completely different, compared to the previous one. The dark front presented a horizontal wavelength of $42 \mathrm{~km}$, observed phase speed and period around $77 \mathrm{~m} / \mathrm{s}$ and $9 \mathrm{~min}$, respectively.

In the mesosphere, fronts are generally uncommon at high latitudes. These waves are more often observed at low and middle latitudes and have been extensively discussed by Taylor et al. (1995), Medeiros et al. (2001), Smith et al. (2003) and Fechine et al. (2005, 2009). At high latitudes, only one case study has reported the existence of a front, which was classified as a mesospheric bore by Nielsen et al. (2006). In that case study, the authors mentioned the occurrence of 5 potential mesospheric bores, within more than 400 gravity waves, observed during the winter periods in Antarctica. In our observations, at least 3 mesospheric fronts within $\sim 240$ gravity waves recorded during six months in 2007 were identified. It represents only $\sim 1 \%$ of the observed gravity waves,
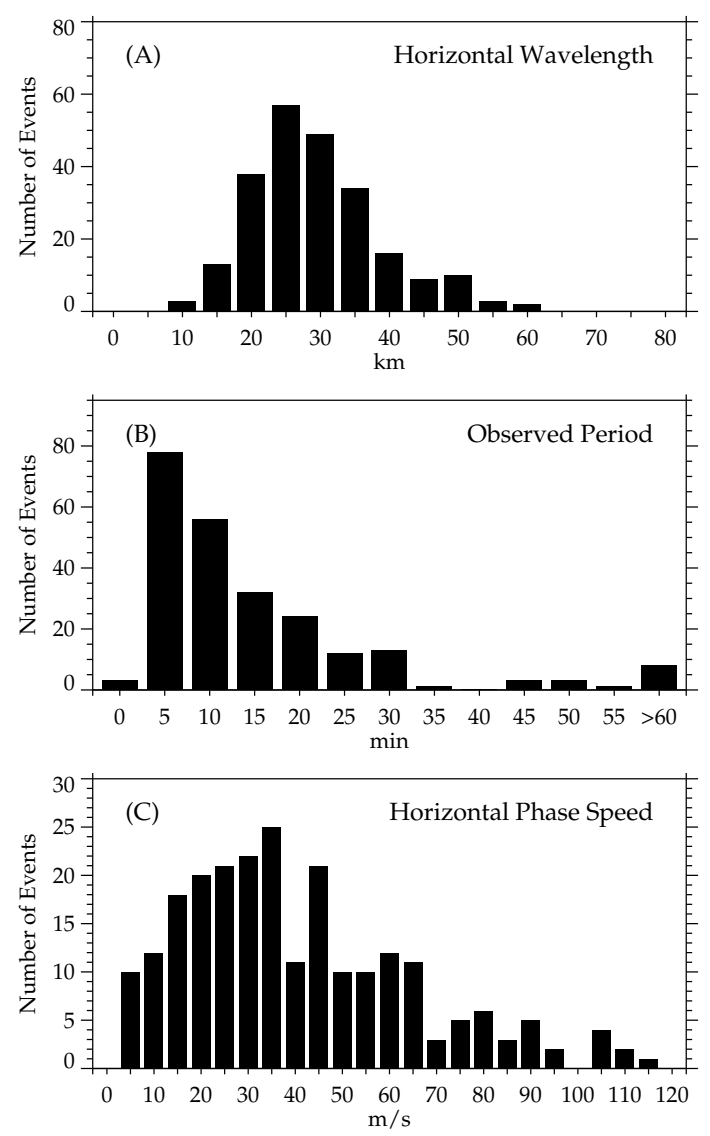

Fig. 3. Histogram plots of the gravity wave characteristics. The panels show, from top to bottom, the horizontal wavelength, observed period and horizontal phase speed.

which supports the idea that mesospheric fronts are unusual at high latitudes.

In a forthcoming paper, we will describe the characteristics of the observed mesospheric fronts, including the atmospheric background conditions, wind and temperature fields in which these waves propagate.

\subsection{Gravity wave characteristics}

Figure 3 presents the characteristics of all 234 gravity waves observed at $\mathrm{CF}$, excluding the solitary pulses and fronts as those shown in Fig. 2c-e. The histograms show the distribution of the horizontal wavelength, observed phase speed and period.

The horizontal wavelengths were distributed from 10 to $60 \mathrm{~km}$, with a maximum occurrence between 15 and $35 \mathrm{~km}$. The observed periods were mainly distributed between 5 and $20 \mathrm{~min}$, but the maximum period was higher than $60 \mathrm{~min}$. The observed phase speed has a distribution that extends from 5 to $115 \mathrm{~m} / \mathrm{s}$. The majority of the waves had velocities between 10 and $65 \mathrm{~m} / \mathrm{s}$. 

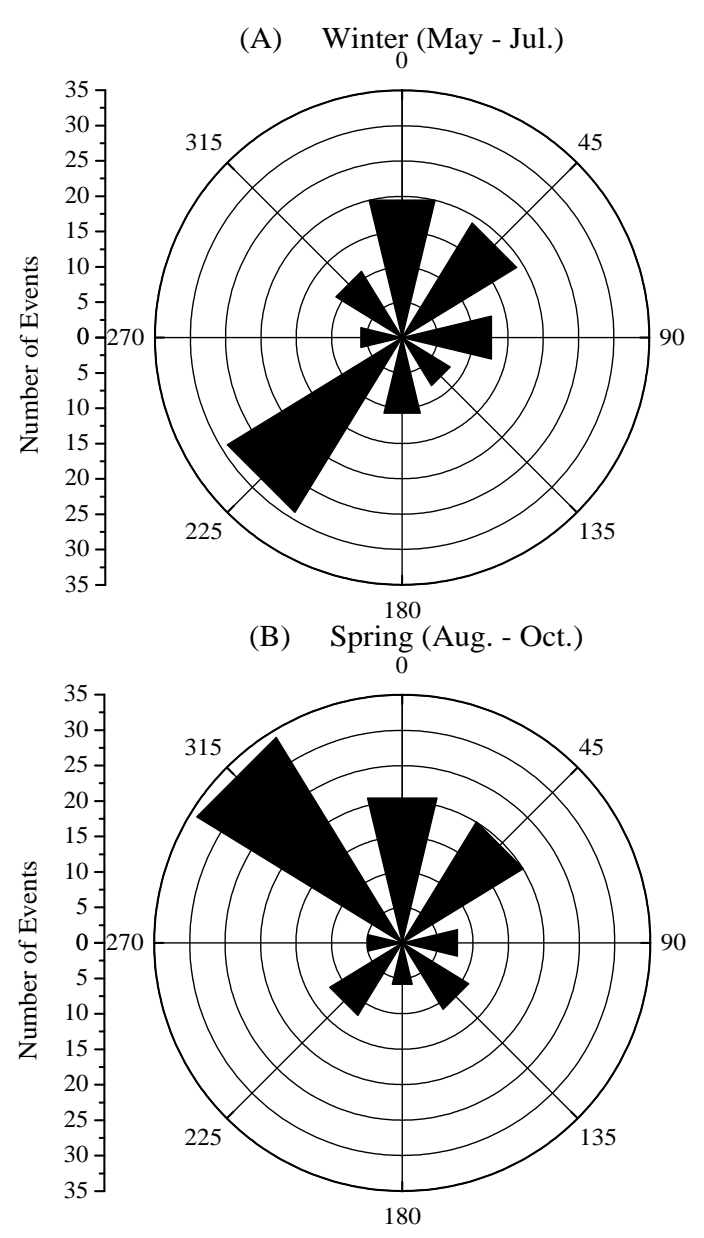

Fig. 4. Polar plots showing the seasonal variation for gravity wave propagation directions observed at CF.

The gravity waves observed at $\mathrm{CF}\left(62^{\circ} \mathrm{S}\right)$ showed similar behavior to those observed at others latitudes. Medeiros et al. (2004) compared the results between two latitudes in Brazil, Cachoeira Paulista $\left(23^{\circ} \mathrm{S}\right.$, hereafter $\left.\mathrm{CP}\right)$ and Cariri $\left(7^{\circ} \mathrm{S}\right)$. Similar analyses were reported by Nakamura et al. (1999) and Nakamura et al. (2003), at Shigaraki ( $\left.35^{\circ} \mathrm{N}\right)$ Japan and at Tanjungsari $\left(6.9^{\circ} \mathrm{S}\right.$, hereafter TJS) Indonesia, respectively.

Wrasse et al. (2006) compared the gravity wave characteristics for 4 distinct stations at equatorial and mid-latitudes. They showed that the horizontal wavelengths observed at $\mathrm{CP}$ and Cariri were similar, with a maximum occurrence between 5 and $25 \mathrm{~km}$; at TJS the horizontal wavelength was mainly distributed between 5 and $30 \mathrm{~km}$, while at Shigaraki was between 5 and $40 \mathrm{~km}$. At CF the horizontal wavelengths were mainly between 15 and $40 \mathrm{~km}$, which were closer to the results presented at Shigaraki. The observed period at $\mathrm{CP}$ and Shigaraki has a maximum occurrence between 5 and $15 \mathrm{~min}$, similar to those observed at Cariri (5 and $10 \mathrm{~min}$ ). The maximum occurrence of the observed periods at CF (5$20 \mathrm{~min}$ ) was larger than at low and mid-latitude sites. At
(A) Winter (May-Jul.)

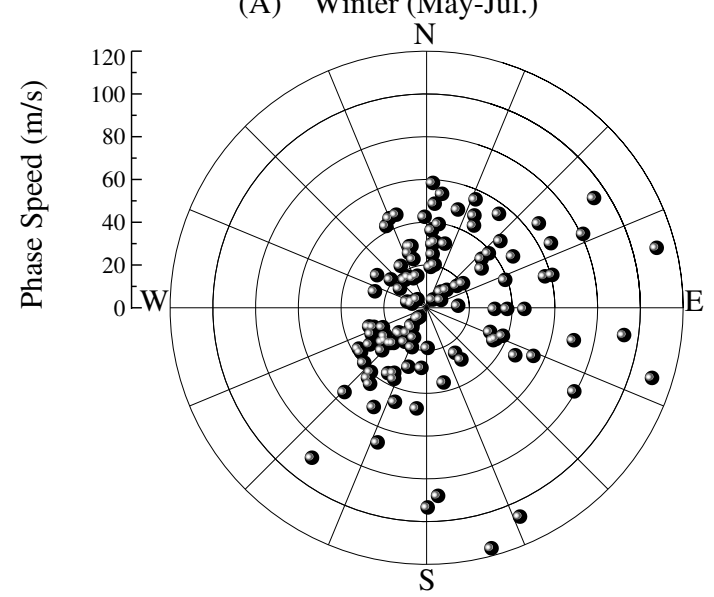

(B) Spring (Aug.-Oct.)

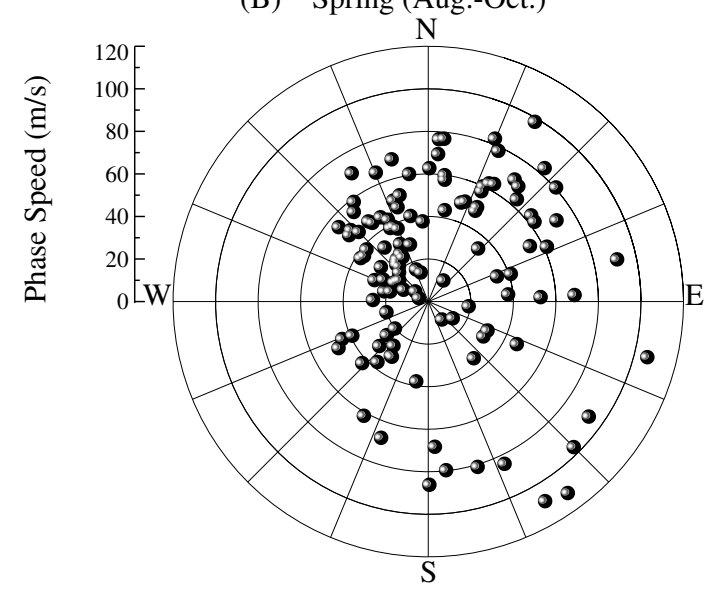

Fig. 5. Distribution of the gravity waves propagation direction as a function of the observed phase speed.

Cariri the gravity waves presented an observed phase speed $(10-55 \mathrm{~m} / \mathrm{s})$ larger than CP $(15-40 \mathrm{~m} / \mathrm{s})$; at TJS the waves were also faster $(30-70 \mathrm{~m} / \mathrm{s})$ than at Shigaraki $(10-70 \mathrm{~m} / \mathrm{s})$. The observed phase speed at CF $(10-65 \mathrm{~m} / \mathrm{s})$ is similar to those observed at Cariri and Shigaraki.

The difference between the gravity wave parameters observed at these different sites could not be attributed to the difference between the equipment. The errors of the observed wave parameters are much smaller than the instrumental limitations of the imagers. It is most probable that the observed differences are due to the difference in geographic latitude between the sites, where the background wind velocities are different (Wrasse et al., 2006).

Although our measurements at CF were limited by a 6 months campaign, the observed gravity wave parameters were similar to other airglow observations sites at low and mid-latitudes in both hemispheres. 


\subsection{Gravity wave propagation direction}

In order to discuss the seasonal variation of the gravity wave propagation direction at $\mathrm{CF}$, the observations were divided in two seasons, winter (May to July) and spring (August to October). In winter, Fig. 4a, it can be observed that the waves propagated in all directions and an anisotropy is observed with most of the waves $(\sim 30 \%)$ propagating to southwest (poleward). During spring, Fig. $4 \mathrm{~b}$, the waves propagate preferentially to northwest, north and northeast directions, showing a clear anisotropy in the wave propagation direction.

The distribution of the gravity wave propagation directions as a function of the observed phase speed is presented in Fig. 5. Each point in the plot represents one observed gravity wave event. The preferred propagation of the waves in each sector can be seen clearly. During winter, the waves with $c_{\mathrm{obs}}<60 \mathrm{~m} / \mathrm{s}$ are propagating preferentially towards the north and southwest, as presented in Fig. 4a. However, the fastest waves with $c_{\mathrm{obs}}>60 \mathrm{~m} / \mathrm{s}(\sim 14 \%)$ propagated mainly to the east. In spring, $\sim 34 \%$ of the waves showed higher phase speed, propagating towards the northeast. The distinct gravity wave propagation directions and phase speed showed in Figs. 4 and 5, may be related to different generation mechanisms.

Gravity waves are mainly generated in the troposphere by several different sources, such as wind flow over mountains (orographic forcing), latent heat releases from convective regions, wind shear associated with jet streams and cold fronts. One of the factors that affect the gravity wave propagation direction is the distribution of wave sources around the observation site (Hecht et al., 2001), which may explain the preferential gravity wave propagation directions observed at CF.

The most likely wave source for the gravity waves observed at CF could be associated to orographic forcing, cold fronts or strong cyclonic activity in that region. Future studies will focus on identifying the main sources of the gravity waves at $\mathrm{CF}$.

\section{Summary}

Mesospheric gravity waves were observed at Comandante Ferraz Antarctica Station $\left(62.1^{\circ} \mathrm{S}, 58.4^{\circ} \mathrm{W}\right)$, using an allsky imager to observe the $\mathrm{OH}$ airglow emission. A campaign was performed over six months from April to October 2007. The main gravity wave characteristics are: (a) horizontal wavelengths ranged from 10 to $60 \mathrm{~km}$, with the majority of waves being between 15 and $35 \mathrm{~km}$; (b) periods ranged from 5 to more than $60 \mathrm{~min}$, with predominant values between 5 and $20 \mathrm{~min}$; and (c) observed phase speeds reached a maximum of $115 \mathrm{~m} / \mathrm{s}$, but more typical velocities were between 10 and $65 \mathrm{~m} / \mathrm{s}$. These characteristics are similar to those previously observed by others authors at low and mid-latitude sites. The propagation directions of the waves showed an anisotropic distribution, with most of them propagating to southwest in winter and to northwest during spring. The fastest gravity waves $\left(c_{\mathrm{obs}}>60 \mathrm{~m} / \mathrm{s}\right)$ showed a predominant propagation direction to the east during winter and to the northeast in spring. Unusual waves were also observed like the solitary pulses and mesospheric fronts which will be further investigated in a forthcoming paper.

Acknowledgements. This research was supported by CNPq/PROANTAR under project $n^{\circ}$ 55.7304/2005-9. J. V. Bageston thank to $\mathrm{CNPq}$ for $\mathrm{PhD}$ scholarship under process $140066 / 2006-3$. C. M. Wrasse thank to CNPq for the grant 304277/2008-8. The authors thank to SECIRM and Brazilian Antarctic Program (PROANTAR) for the opportunity to develop research at Comandante Ferraz Antarctica Station. In particular, we thank to J. R. Chagas and A. T. Hadano for their help during the last 2 months of the campaign.

Topical Editor C. Jacobi thanks A. Fragoso de Meideiros and another anonymous referee for their help in evaluating this paper.

\section{References}

Espy, P., Jones, G., Swenson, G., Tang, J., and Taylor, M. J.: Seasonal variations of gravity wave momentum flux in the Antarctic mesosphere and lower thermosphere. Geophys. Res. Lett., 109, 1-9, 2004.

Fechine, J., Medeiros, A. F., Buriti, R. A., Takahashi, H., and Gobbi, D.: Mesospheric bore events in the equatorial middle atmosphere, J. Atmos. Solar-Terr. Phys., 67, 1774-1778, 2005.

Fechine, J., Wrasse, C. M., Takahashi, H., Medeiros, A. F., Batista, P. P., Clemesha, B. R., Lima, L. M., Fritts, D., Laughman, B., Taylor, M. J., Pautet, P. D., Mlynczak, M. G., and Russell, J. M.: First observation of an undular mesospheric bore in a Doppler duct, Ann. Geophys., 27, 1399-1406, 2009, http://www.ann-geophys.net/27/1399/2009/.

Fritts, D. C., and Alexander, M. J.: Gravity wave dynamics and effects in the middle atmosphere, Rev. Geophys., 41, 1003, doi:10.1029/2001RG000106, 2003.

Garcia, F. J., Taylor, M. J., and Kelly, M. C.: Two-dimensional spectral analysis of mesospheric airglow data, Appl. Optics, 36, 7374-7385, 1997.

Hecht, J. H., Walterscheid, R. L., Hickey, M., and Franke, S.: Climatology and modeling of quasi-monochromatic atmospheric gravity waves observed over Urbana Illinois, J. Geophys. Res., 106(D6), 5181-5196, 2001.

Hibbins, R. E., Espy, P. J., Jarvis, M. J., Riggin, D. M., and Fritts, D. C.: A climatology of tides and gravity wave variance in the MLT above Rothera, Antarctica obtained by MF radar, J. Atmos. Solar-Terr. Phys., 69, 578-588, 2007.

Medeiros, A. F., Taylor, M. J., Takahashi, H., Batista, P. P., and Gobbi, D.: A unusual airglow wave event observed at Cachoeira Paulista $23^{\circ}$ S, Adv. Space Res., 27, 1749-1754, 2001.

Medeiros, A. F., Taylor, M. J., Takahashi, H., Batista, P. P., and Gobbi, D.: An Investigation of gravity wave activity in the low-latitude upper mesosphere: propagation direction and wind filtering, J. Geophys. Res., 108(D14), 4411, doi:10.1029/2002JD002593, 2003. 
Medeiros, A. F., Buriti, R. A., Machado, E. A., Takahashi, H., Batista, P. P., Gobbi, D., and Taylor, M. J.: Comparison of gravity wave activity observed by airglow imaging at two different latitudes in Brazil, J. Atmos. Solar-Terr. Phys., 66, 647-654, 2004.

Nakamura, T., Higashikawa, A., Tsuda, T., and Matsushita, Y.: Seasonal variations of gravity wave structures in $\mathrm{OH}$ airglow with a CCD imager at Shigaraki, Earth Planets Space, 51, 897-906, 1999.

Nakamura, T., Aono, Tsuda, T., Admiranto, A. G., Achmad, E., and Suranto: Mesospheric gravity waves over a tropical convective region observed by $\mathrm{OH}$ airglow imaging in Indonesia, Geophys. Res. Lett., 30, 1882-1885, 2003.

Nielsen, K., Taylor, M., Stockwell, R., and Jarvis, M.: An unusual mesospheric bore event observed at hight latitudes over antarctica, Geophys. Res. Lett., 33, 803, doi:10.1029/2005GL025649, 2006.

Smith, S. M., Taylor, M. J., Swenson, G. R., She, C., Hocking, W., Baumgardner, J., and Mendillo, M.: A multidiagnostic investigation of the mesospheric bore phenomenom, J. Geophys. Res., 108(A2), 1083, doi:10.1029/2002JA009500, 2003.
Stockwell, R., Taylor, M., Nielsen, K., and Jarvis, M. A.: A novel joint space-wavenumber analysis of an unusual Antarctic gravity wave event, Geophys. Res. Lett., 33, L08805, doi:10.1029/2005GL025660, 2006.

Taylor, M. J., Turnbull, D. N., and Lowe, R. P.: Spectrometric and imaging measurements of a spectacular gravity wave event observed during the ALOHA-93 campaign, Geophys. Res. Lett., 20, 2849-2852, 1995.

Wrasse, C. M., Nakamura, T., Takahashi, H., Medeiros, A. F., Taylor, M. J., Gobbi, D., Denardini, C. M., Fechine, J., Buriti, R. A., Salatun, A., Suratno, Achmad, E., and Admiranto, A. G.: Mesospheric gravity waves observed near equatorial and low-middle latitude stations: wave characteristics and reverse ray tracing results, Ann. Geophys., 24, 3229-3240, 2006, http://www.ann-geophys.net/24/3229/2006/.

Wrasse, C. M., Takahashi, H., Medeiros, A. F., Lima, L. M., Taylor, M. J., Gobbi, D., and Fechine, J.: Determinação dos parâmetros de ondas de gravidade através da análise espectral de imagens de aeroluminescência, Braz. J. Geophys., 25, 257-266, 2007. 